Sandford R. Holdahl

National Geodetic Survey

National Ocean Survey/NOAA

Rockville, Maryland 20782

\title{
INTRODUCTION
}

Refraction error is often regarded as the most serious problem with geodetic leveling. Its accumulation depends on the slope of the terrain being leveled, length of sight, and the vertical temperature gradient. Refraction error can be minimized by limiting and balancing sight lengths, and by not reading the portion of the level rod which is within 0.5 meter of the ground where air density changes mosit rapidly. The remaining refraction error should be removed by application of a correction to leveling data, otherwise heights and crustal motion may be determined so weakly that meaningful conclusions or interpretations cannot be inferred from the data by geophysicists.

A refraction correction for leveling was first developed by T. J. Kukkamaki (Kukkamaki 1937). Ironically, Finland is not one of the countries that most needs a remedy for refraction error. The vertical temperature gradients in Finland are not as large as those found to the south, terrain relief is not severe, and sight lengths used in Finland are limited to a distance, which is shorter than the limit used by most countries. However, Finland is noted for the high quality of its leveling. The leveling data are used to resolve geophysical problems and to estimate post-glacial uplift, and, therefore, must be very accurate. Finnish geodesists developed instrumentation to measure vertical temperature differences while leveling is underway, and gained confidence in the temperature function which is the basis for the correction.

Most countries have been reluctant to utilize the refraction correction. This is probably due to several factors: (1) extra instrumentation and computational effort are required, (2) disbelief in the idea that temperature in the lowest 3 meters can be represented by a single temperature function, and (3) belief that refraction error is small. The full effect of leveling refraction is normally not seen in misclosures between forward and backward levelings because it is usually common to both in approximately the same amount. Similarly, circuit

305

E. Tengström and G. Teleki (eds.), Refractional Influences in Astrometry and Geodesy, 305-319. Copyright $\odot 1979$ by the IAU. 
misclosures do not reveal the total refraction error, consequently it is sometimes underestimated.

It has also been thought that only mountainous countries suffer from significant accumulations of refraction error; and then, only the heights of the mountain peaks would be in serious error.

A recent experiment was conducted in California by the author to determine whether refraction error in locations with low latitudes and arid climates might be considerably greater than in Finland or England. The experiment was performed in December when temperature gradients should be smallest. Observed vertical temperature differences averaged 4-10 times as large as those predicted by a table developed by A. C. Best (Best 1937). The Best table gives hourly values of $\Delta t$, for each month, between the heights of $30 \mathrm{~cm}$ and $120 \mathrm{~cm}$, and is based on means of 2 years of continuous observation in England. The high $\Delta t$ values observed in California are alarming because they indicate, provided the existing refraction correction is valid, that refraction error in California and probably the remainder of the United States is much greater than was assumed previously.

A further objective of the experiment was to see whether vertical temperature gradients were larger on south slopes (i.e. slopes facing down to the south) than on north slopes (i.e. slopes facing down to the north). Simultaneous observations on north and south slopes revealed that south slopes gave vertical temperature differences, between heights of $50 \mathrm{~cm}$ and $250 \mathrm{~cm}$, that averaged $.89^{\circ} \mathrm{C}$ higher than north slopes. This result is disconcerting because it means that refraction error accumulated while leveling up the south slope of a topographical feature will generally not be canceled adequately by refraction error of the opposite sign accumulated while leveling down the north side. In mid-latitudes, refraction error will systematically accumulate in the north-south direction as each topographical feature is traversed by leveling.

The vertical temperature difference, $\Delta t$, is an essential parameter in the refraction correction. Because present methods for estimating $\Delta t$ do not consider the angle at which the sun's rays strike the ground, or consider regional and seasonal variation in cloud cover or turbidity of the atmosphere, the authorsuggests the use of solar radiation measurements as a basis for estimating $\Delta t$. The formulas in the latter section of this paper are used to compute the orientation and slope of the terrain surface relative to the sun's rays.

\section{THE REFRACTION CORRECTION}

The refraction correction, $R$, in $\mathrm{mm}$, for a single setup of the instrument is given by:

$$
\mathrm{R}=-10=5 \cdot \mathrm{A} \cdot \frac{\mathrm{L}}{50}^{2} \cdot \Delta \mathrm{t} \cdot \Delta \mathrm{h}
$$


$A=$ a function tabulated by Kukkamki for each month, each hour and the respective geographic latitude, depending on the exponent $c$ of the used temeprature function $t=a+b z^{c}$, the altitude $z$ of the temperature measuring places, and the height of the instrument above the ground. Mean values for $c$ were derived from temperature measurements by Best. A is frequently assumed constant, and equal to 70 ;

$L=$ sighting distance at station in meters;

$\Delta t=$ temperature difference $\left(t_{2}-t_{1}\right)$ between the heights of the temperature measuring stations $z_{1}=50 \mathrm{~cm}$ and $z_{2}=250 \mathrm{~cm}$ in degrees celsius;

$\Delta h=$ measured height difference in $0.5 \mathrm{~cm}$ units.

When the temperature difference, $\Delta t$, is observed, the correction is determined at each instrument station and accumulated over the whole section. This is the most rigorous application of the refraction correction.

When used to refine historical leveling data, the correction relies on estimation of $\Delta t$ because air temperature measurements were traditional: not made at more than one height. The $\Delta t$ is assumed to be constant for each setup of the instrument in the leveled section. Sight lengths and measured height differences are also assumed to be the same at each setup. Average values of $L$ and $\Delta h$ are calculated by an algorithm. The correction for the average setup is then multiplied by $n$, the number of setups, to obtain the correction for the whole section.

$$
\mathrm{R}=-10^{-5} \cdot \mathrm{A} \cdot\left(\frac{\overline{\mathrm{L}}}{50}\right)^{2} \cdot \bar{\Delta} \mathrm{t} \cdot \bar{\Delta} \mathrm{h} \cdot \mathrm{n}
$$

where $\overline{\mathrm{L}}, \bar{\Delta} \mathrm{t}$, and $\bar{\Delta} \mathrm{h}$ are the average setup values for sight length, vertical temperature difference, and observed height difference. The number of setups, $n$, is available from the leveling records.

It can be seen from equation (1) that refraction error would be negligible on flat terrain or when cloud cover minimizes $\Delta t$. Conversely, on clear days, large refraction errors will accumulate when leveling on sloping terrain. It is also important to note that the refraction correction is proportional to the square of the sighting distance. This implies that the leveling specification, which defines the maximum sight length will have considerable influence on the amount of refraction error that may accumulate in leveling. The poorest conditions for leveling, from the viewpoint of refraction, will generally exist on clear days, at noon, when leveling with long sight lengths on a gentle slope. 
In the temperature function used by Kukkamaki, given below,

$$
t=a+b z^{c}
$$

where, $a$ and $b$ are constants, and $z$ is height above the ground, the coefficient $c$ has been determined by harmonic analysis using two years of data obtained in England (latitude 51.2) by A. C. Best.

$$
c=f+g\left(T-12^{h}\right) \text {, }
$$

where

$$
E=-0.14+0.10 \sin \left(\frac{360^{\circ}}{365} D-61^{\circ}\right)
$$

and

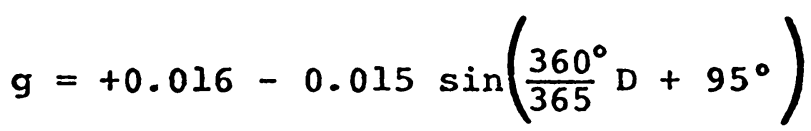

$D$ is the number of days elapsed since the beginning of the year, and $T$ is the hour of observation.

Equation (4) is used, starting at 2.5 hours after sunrise and ending at 0.3 hour before sunset, to calculate the value $A$ in equation (1):

$$
A=\frac{5.95}{z_{2}^{c}-z_{1}^{c}}\left[\frac{1}{c+1}\left(z_{1}^{c+1}-z_{2}^{c+1}\right)+z_{0}^{c}\left(z_{2}-z_{1}\right)\right]
$$

$z_{0}, z_{1}, z_{2}$ are heights of the instrument, the low temperature probe, and the high temperature probe, respectively.

\section{EXPERIMENTATION}

An experiment in California was motivated by concern that $\Delta t$ values interpolated from the English data would be too small. Further, it was hypothesized that $\Delta t$ values on slopes facing down to the south should be larger than those occurring simultaneously on nearby slopes which face down to the north. The results of the experiment showed that both of these concerns were justified.

The California experiment was conducted at several locations for two weeks in December 1977. Temperatures were measured at several heights $(30,50,120$, and $250 \mathrm{~cm})$ above ground. During most of the experiments measurements were made only at heights of $50 \mathrm{~cm}$ and $250 \mathrm{~cm}$ which correspond to $z_{1}$ and $z_{2}$ of equation (7). In precise leveling, the sighting path will normally intercept the leveling rod between these two vertical limits. 
The magnitude of the observed vertical temperature difference frequently exceeded $2^{\circ} \mathrm{C}$ on south slopes, and reached a maximum of $3^{\circ} \mathrm{C}$ on a clear day with light breeze. The maximum value that can be obtained for December from interpolation using the Best Table is $0.3^{\circ} \mathrm{C}$. Throughout most of the experimentation observed values exceeded the corresponding tabular values by a factor ranging between 5 and 10 .

On seven days of the experiment, two observers worked simultaneously on opposite sides of a mountain or valley. Comparison of $\Delta t$ values, observed at identical times, showed that values from south slopes averaged $0.89^{\circ} \mathrm{C}$ higher. The significance of this result is that refraction can induce a systematic accumulation of error in the northsouth direction. High refraction error accumulated while going up the south face of a mountain would be insufficiently canceled by lesser refraction error of opposite sign accumulated while leveling down the north face. This accumulation would be almost as great with rolling terrain as it would be for mountains. The sign of the accumulated error is such that it would cause north-directed leveling to yield heights which became increasingly too low as the survey progressed over several hills or mountains.

Figures 1 and 2 are computer plots that depict observed values of $\Delta t$, incident light (scale on right vertical axis), and recommended tabular values of $\Delta t$. The values plotted in figure 1 were observed on a slope which faced down to the south; the values in figure 2 were observed simultaneously on the opposite side of a small valley which sloped down to the north. The sun's rays struck the down-to-south slope much more directly and, therefore, produced steeper temperature gradients. A similar result was observed at several other locations as well. This implies that the method of estimating vertical $\Delta t$ needs to be modified to reflect the incidence angle of the sun's rays.

Figures 1 and 2 also indicate that the tabular values (shown in figure 3 and developed in England by A. C. Best) are not representative for California, and are probably not representative for most of the United States. The depicted tabular values have been used in Finland with some success, but they are much too small for latitudes below $45^{\circ}$ where cloud cover is not prevalent.

The development of an improved table of $\Delta t$ values is a very important undertaking, Vertical crustal movements determined by analysis of old levelings will be influenced by its quality.

\section{SOLAR RADIATION}

The amount or quantity of the sun's radiation reaching a horizontal unit of the earth's surface depends upon a number of factors. These include the intensity of radiation emitted by the sun, astronomical considerations determining the position of the sun, and the transparency of the atmosphere. 
NOI $\perp$ N IWกาาI

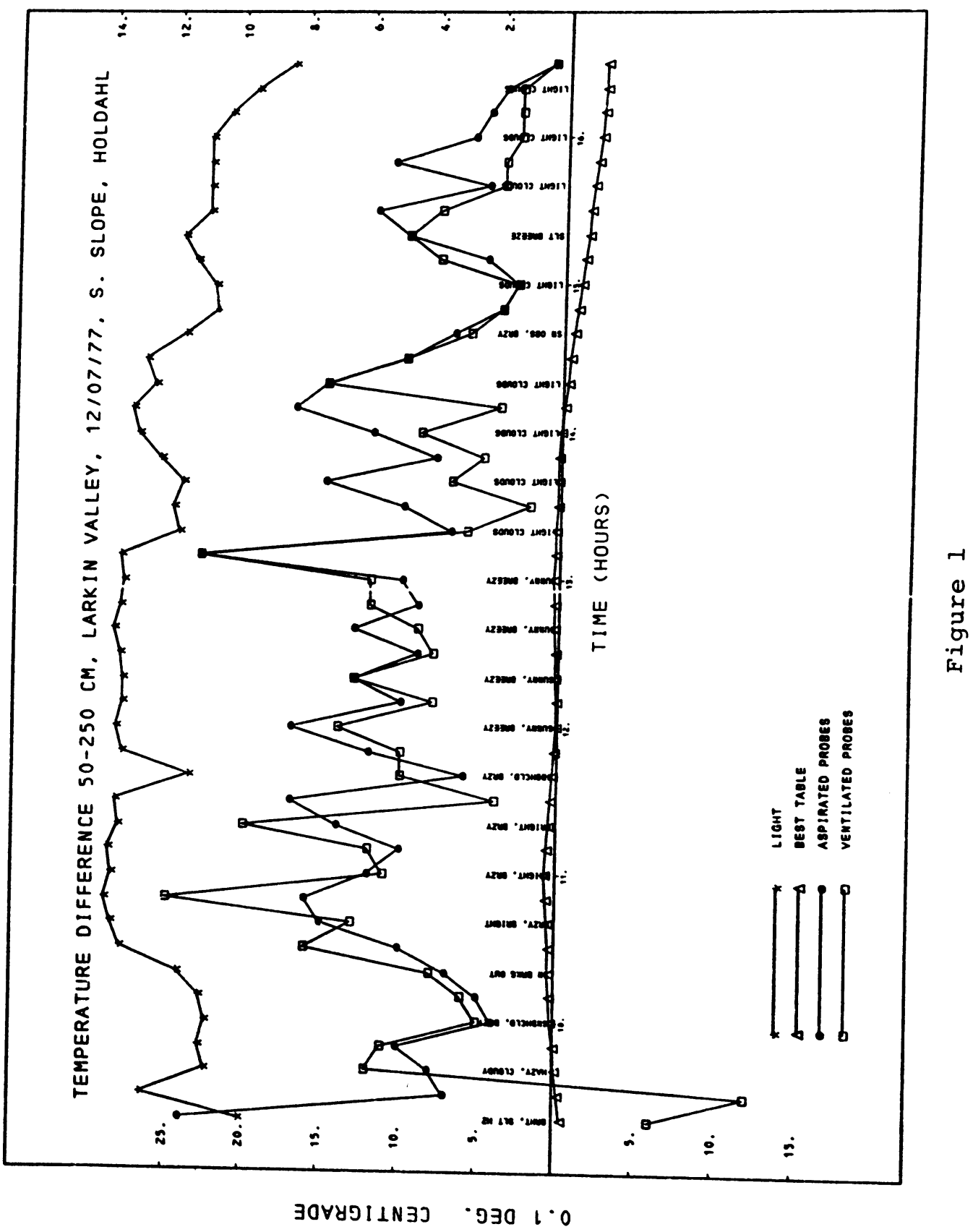


NOI $\perp \forall N I W ก 7 า I$

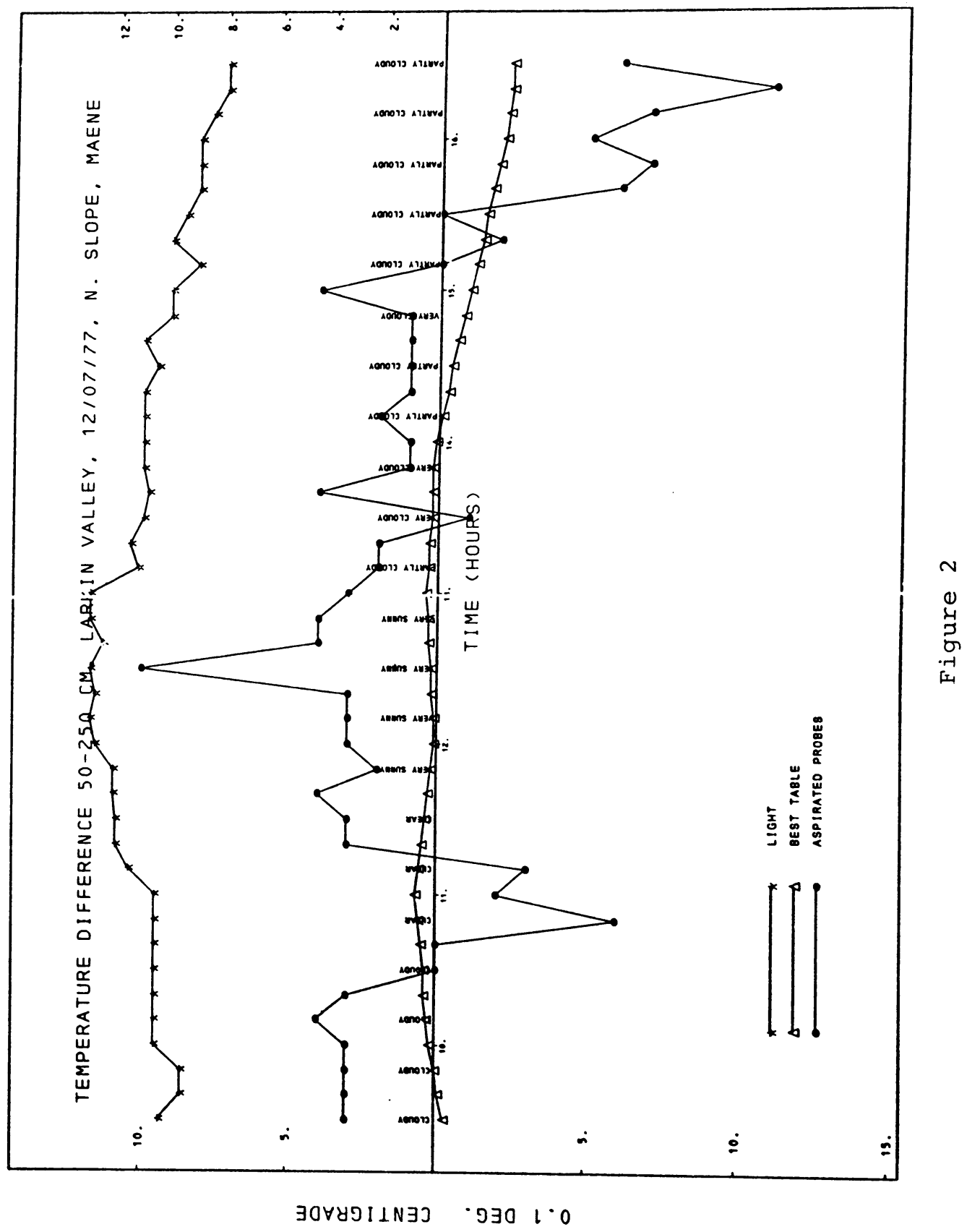




\section{TEMPERATURE DIFFERENCE ${ }^{\circ} \mathrm{C}$ BETWEEN $30 \mathrm{CM}$ AND 120 CM ABOVE GROUND \\ According to A.C. Best.}

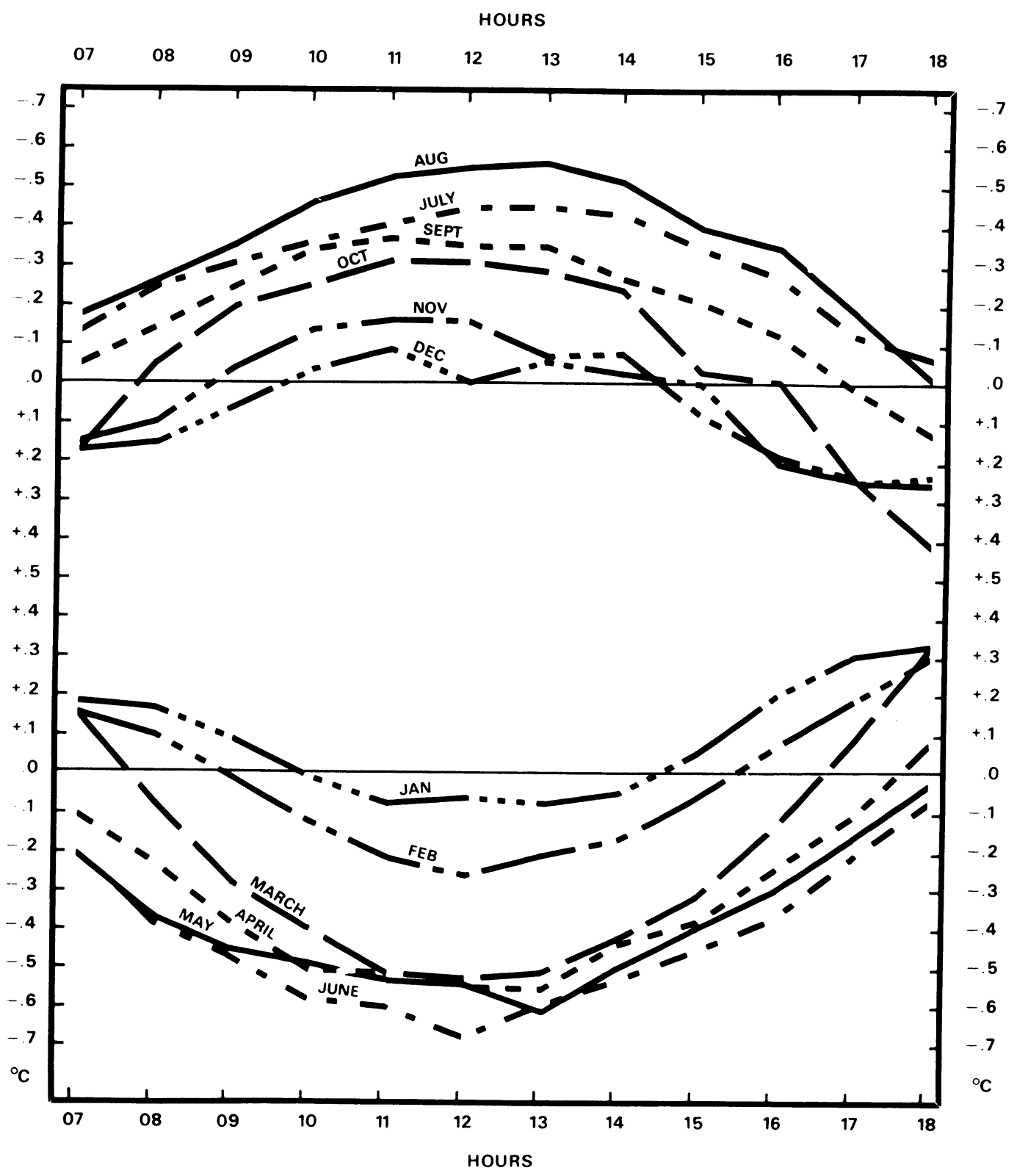

Figure 3 
Vertical temperature gradients are influenced by the amount of solar radiation received by the ground. Vertical temperature gradients, therefore, are governed to a large degree by Lambert's Cosine Law which states "the intensity (of the sun's radiation beam) on the ground varies as the cosine of the angle between the normal to the terrain surface and the beam. This means that a solar beam spreads out on a slanted surface and, therefore, the energy received on a unit area of that surface must decrease as the incidence angle decreases from $90^{\circ}$.

The sun's azimuth and zenith distance also determine how much atmosphere a solar beam must pass through before reaching the ground. The atmospheric gases surrounding the earth absorb considerable portions of the direct solar beam.

For the above two reasons, the solar radiation received simultaneously at two different latitudes, or at two locations with the same latitude but different ground slopes, would not be the same. Consequently, any method of estimating values of the vertical $\Delta t$ must consider latitude and ground slope. Latitude, longitude, height difference, distance leveled, and time have traditionally been recorded; and can be used to calculate incidence angle of the sun's rays, zenith distance or declination of the sun, and the azimuths of the sun and level line.

An attractive model for interpolating $\Delta t$, which considers latitude, clouds, and turbidity of the atmosphere can be developed from averages of actual measurements of solar radiation received at the earth's surface. The climatic records of the United States give mean daily totals of solar radiation for each month, determined at 192 stations distributed throughout the United States. Measurements have been made for as long as 46 years at one of the locations, and the average measurement history extends more than 20 years.

A mathematical fitting procedure can be used to find an expression for seasaonal and regional variations in solar radiation. Measurements of solar radiation from Canada may also be used to obtain a result which would be applicable throughout most of North America.

The fitting procedure can proceed by first expressing solar radiation as follows:

$$
\begin{aligned}
S(x, y, D)=P(x, y) & +Q(x, y) \sin (2 \pi D / 365-\pi / 2) \\
& +R(x, y) \cos (2 \pi D / 36 j-\pi / 2)
\end{aligned}
$$

where $D$ is the number of days since December 21. $P(x, y), Q(x, y)$, and $R(x, y)$ are polynomials whose coefficients can be determined by a least squares fit to monthly means of observed daily totals of solar radiation. 
It will be helpful to adopt the following notation:

$\mathrm{S} \quad=$ mean daily total of solar radiation, measured between sunrise and sunset, which is incident on a horizontal surface;

$S^{\prime}=$ instantaneous solar radiation on a horizontal surface;

S" = instantaneous solar radiation on an inclined surface;

$S_{\max }=$ maximum value of solar radiation on a given day

The mean daily total solar radiation, measured on a level surface, must be converted to instantaneous solar radiation on a surface that is usually inclined.

The plotted diurnal variation of solar radiation, between sunrise and sunset has the shape of an inverted parabola, peaking at noon, and zero at approximately one-half hour after sunrise and before sunset (see figure 4 below).

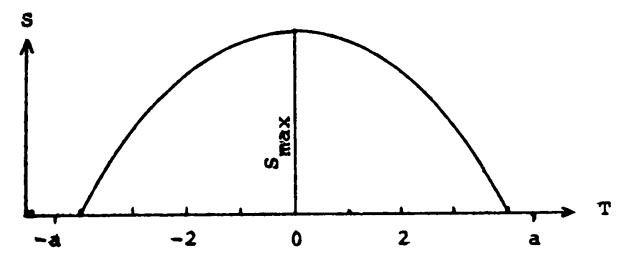

$$
S^{\prime}=S_{\max }-\frac{\mathrm{T}^{2} S_{\max }}{(a-.5)^{2}}
$$

$\mathrm{T}$ is the hour angle of the sun; and, $\mathrm{a}$ is half the number of hours between sunrise and sunset.

The value, a, can be calculated according to

$$
a=\frac{1}{15} \cos ^{-1}(-\tan \delta \tan \phi)
$$

where $\delta$ is the declination of the sun, and $\phi$ is the latitude of the location where releveling is being done. and get

We can integrate (9) to obtain the daily total of energy received,

$$
S=\int_{-a+.5}^{a-.5}\left(S_{\max }-\frac{T^{2} S_{\max }}{(a-.5)^{2}}\right) d t=\frac{4(a-.5) S_{\max }}{3}
$$


Rearranging,

$$
S_{\max }=\frac{3 S}{4(a-.5)}
$$

Substituting (12) into (9) allows us to calculate S', the instantaneous solar radiation on a level surface:

$$
S^{\prime}=\frac{3 S}{i(a-.5)}\left[1-\left(\frac{T}{a-.5}\right)^{2}\right]
$$

The following equation uses a variation of Lambert's Cosine Law to convert the instantaneous solar radiation, $S^{\prime}$, on a level surface to solar radiation, $S^{\prime \prime}$, received on an inclined surface:

$$
S^{\prime \prime}=\frac{S^{\prime} \sin B_{1}}{\sin B_{0}}
$$

$B_{0}$ is the incidence angle between the sun's rays and a level surface, and $B_{1}$ is the incidence angle between the sun's rays and the ground surface.

$$
B_{0}=90^{\circ}-\gamma
$$

where $\gamma$ is the zenith distance of the sun, and

$$
\begin{aligned}
\sin B_{1}= & \cos \gamma \cos |\alpha|+\sin \gamma \sin |\alpha| \cos (D A Z) \\
& \text { if } \alpha \leq 0, D A Z=A^{*}-A^{\prime} \\
& \text { if } \alpha>0, D A Z=A^{*}-A^{\prime}-\pi
\end{aligned}
$$

where $x$ is the slope of the terrain surface, and is given by

$$
\alpha=\tan ^{-1} \frac{(\Delta \mathrm{h})}{2 \mathrm{~L}}
$$

$\Delta h$ is the observed height different, and $\mathrm{L}$ is the sight length. $A^{*}$ and $A^{\prime}$ are the azimuths of the sun and level line, respectively.

\section{THE VERTICAL TEMPERATURE PROFILE}

A vertical temperature profile can be constructed from a knowledge of solar radiation by first converting solar radiation to net radiation, $s_{n}$, using the following expression (Rosenberg 1974):

$$
s_{n}=0.85 s^{\prime \prime}-0.14
$$


NOI $\perp \forall N I$ Nกา7 I

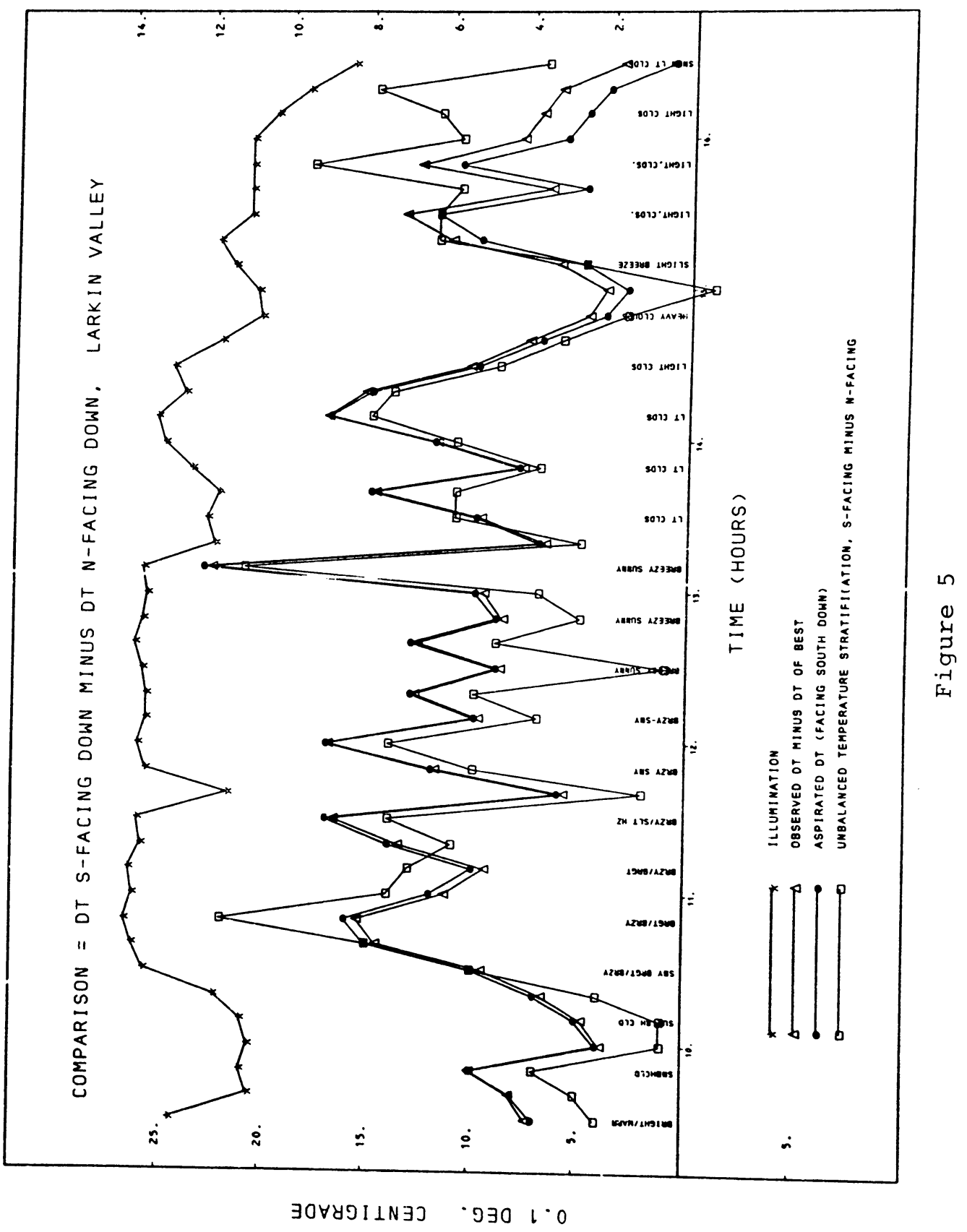


Net radiation combines with heat flux into the ground, G, to yıeld upward sensible heat flux, $\mathrm{H}$ :

$$
H=\left(S_{n}-G\right)-\lambda E
$$

where $\lambda E$ is the evaporation flux with $E$ the evaporation rate and $\lambda$ the latent heat of vaporization of water. equation:

Heat flux into the ground is estimated using the following

$$
G=A_{0} K_{0} \sin (w C+\pi / 4)
$$

$A_{0}$ is the amplitude of the daily surface temperature, $K_{0}$ is the thermal conductivity of the soil, and $t$ is the time in hours from the time of maximum temperature, and $w=2 \pi / 24$, the period of the cycle being 24 hours.

The temperature $\mathrm{T}_{\mathrm{h}_{1}}$ at height $\mathrm{h}_{1}$ can be calculated with the following
tion: equation:

$$
\mathrm{T}_{\mathrm{h}_{\mathrm{l}}}=\mathrm{T}_{\mathrm{h}}+3\left[\frac{\mathrm{h}^{2} \mathrm{~T}_{\mathrm{h}}}{\left(\mathrm{C}_{\mathrm{p} \rho}\right)^{2 \mathrm{~g}}}\right]^{1 / 3}\left(\mathrm{~h}_{1}^{-1 / 3}-\mathrm{h}^{-1 / 3}\right)-.0098\left(\mathrm{~h}_{\mathrm{l}}-\mathrm{h}\right)
$$

where $C_{p}$ is the specific heat of air at constant pressure

0 is the density of $\operatorname{air}\left(c_{p} p=1200\right)$

$\mathrm{h}$ is the height at which $\mathrm{T}_{\mathrm{h}}$ is measured

$\mathrm{g}$ is. the acceleration due to gravity, $\mathrm{m} / \mathrm{sec}^{2}$

To obtain the temperature difference between two heights equation (21) is applied twice to obtain:

$\Delta t=T_{h_{2}}-T_{h_{1}}=3\left[\frac{H^{2} T_{h}}{\left(C_{p} \rho\right)^{2} g}\right]^{1 / 3}\left(h_{2}^{-1 / 3}-h_{1}^{-1 / 3}\right)-.0090\left(h_{2}-h_{1} ;\right.$

In the above two equations $\mathrm{T}_{\mathrm{h}}$ is the air temperature in ${ }^{\circ} \mathrm{K}$ and can be obtained from the old leveling records where it was needed to correct for expansion or contraction to the graduation invar strips of the level rods. The height, $h$, would ordinarily be 1.5 meters.

Equations (19), (20), and (21) were presented with more detailed djscussion by Webb (1969), and later by Angus-Leppan $(1970 ; 1971)$ and Angus-Leppan and Webb (1971): The equations were suggested for reducing EDM measurements, being applicable for heights from less than a meter above the ground, uf to tens of meters. Consequently, they should also be suitable for estimating $\Delta t$ for input to the refraction correction tor leveling. 
If we ignore for the moment the need to know the evaporation flux, $\lambda E$, in equation (19), we can say that a method for estimating the vertical temperature difference, $\Delta t$, is possible even when only one air temperature, $\mathrm{T}_{\mathrm{h}}$, has been measured. However, $\lambda \mathrm{E}$ can be very important in lower latitudes where there is normal or above average precipiation. It is less important at higher latitudes or in arid climates. In moist areas, $\lambda E$ can range between $25-50 \%$ of $\mathrm{s}_{n}$, and range between $5-25 \%$ of $s_{n}$ in arid regions. It may be possible to model $\lambda$ E using weather data obtained over a period of years, as has been done with solar radiation data. The author has not yet explored this and other possibilities.

As of this writing, the above method of estimating $\Delta t$ has not been tested. The described method is regarded as tentative and is being presented for discussion. Testing will begin in the coming months.

\section{REFERENCES}

Angus-Leppan, P.V.: 1970, Proc. Conf. on Densification of Geodetic Networks, Budapest.

Angus-Leppan, P.V.: 1971, Commonwealth Survey Officers Conference, Paper No. 85, 9.

Angus-Leppan, P.V. and Webb, E.K.: 1971, General issembly IUGG, Hoscow, Section 1, 15.

Best, A.C.: 1935, Geophysical Memoirs No. 65, London.

Fraser, C.S.: 1977, Uniserv G 27 (1977), p. 42-51, Univ. NSW, Sydney. Geiger, R.: 1975, Harvard University Press.

Hytonen, E.: 1967, Pub. of the Finnish Geodetic Inst., No. 63, Helsinki. Kukkamaki, T.J.: 1936, Verh. d. 9. Tagung d. Balt. Geod. Komm., Helsinki and Helsinki 1937.

Rosenberg, N.J.: 1974, John Wiley \& Sons, New York.

Webb, E.K.: 1969, Proc. of REF-EDM Conf., Univ. NSW, Sydney (1968), 1-9.

\section{DISCUSSION}

D.G. Currie: Have you compared this effect of actual lumination on the data? It would appear, that your 0.89 degree difference may have been explained by the fact that you had a different lumination on your north and south slope, and therefore have become a direct confirmation of the other things you were talking about.

S.R. Holdahl: The 0.89 degree difference is well explained by Lambert's Cosine Law. The radiation on south slopes is more intense because the ground is more normal to the sun's rays at latitudes higher than $23^{\circ}$.

o. Remmer: I only have a simple question. I am planning to make test measurements in small networks, where I can use your formula for significantly reducing the mean errors. Do you think it is worth while to do that? 
S.R. Holdahl: No. I suggest that you measure $\Delta t$ and plug it into Kukkamäki's formula for leveling refraction. My method of predicting $\Delta t$ should be used for removing the influence of refraction from old leveling measurements obtained without measuring $\Delta t$.

J.C. de Munck: In the United States there is a systematic difference between the levellings near sea-level and those on land. Can the mentioned effect be an explanation for that?

S.R. Holdahl: Unfortunately, correcting for differing amounts of radiation on north and south slopes will make a larger disagreement between the older levelings and the oceanographically determined sea slopes. The most recent coastal leveling in California would be improved by it.

P.V. Angus-Leppan: This is an interesting approach, which could be used for future levelling as well. Do you think, that you should measure the actual temperature differences? Would it not be better to use the heat balance approach, in which case the measurements would be qualitative ones, e.g. cloudiness type of surface, moisture, and perhaps wind?

S.R. Holdahl: I don't think that modeling of $\Delta t$ could be as reliable as measuring it, but it would be more convenient. It would be necessary to record all the parameters you just mentioned before the modeled $\Delta t$ is comparable, and it is probably easier to just measure $\Delta t$.

T.J. Kukkamäki: Remmer asked, whether you are making some test measurements. I understand that you can test your method easily. You have the direct measurements of temperature differences, and you have recordings of cloudiness, and you can compare your theoretical values with the directly observed values. If you see - and that's an answer to AngusLeppan - that the theoretical computation gives good results enough, then you stop your observations as unnecessary ones.

S.R. Holdahl: Exactly! 